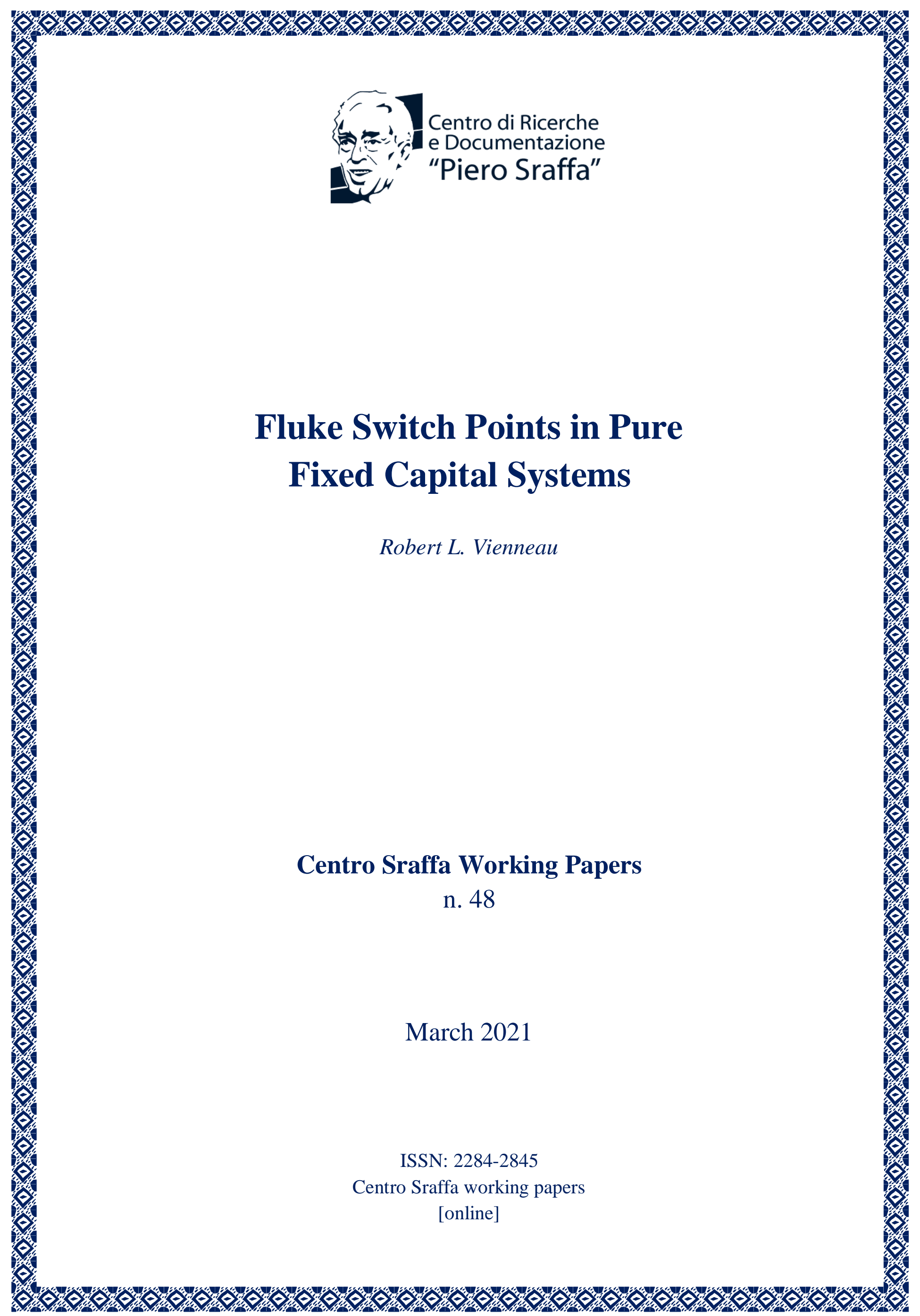




\title{
Fluke Switch Points in Pure Fixed Capital Systems
}

\author{
Robert L. Vienneau \\ Independent Researcher
}

\begin{abstract}
This article considers structural economic dynamics, in models with fixed capital and a choice of technique, of the production of commodities. Fluke switch points are described and catalogued. For fluke switch points, parameter perturbations create a qualitative change in how the choice of technique varies with distribution. Techniques are presented for visualizing partitions of parameter spaces such that the analysis of the choice of technique does not vary within each region. Implications are drawn about the choice of the truncation of the operation of (or the economic life of) machines and about the adoption of roundabout techniques.
\end{abstract}

Keywords: Fixed capital; Choice of technique; Cambridge Capital Controversy; Structural dynamics.

JEL Classification: B51; B53; C67; D24; D33; O33.

\section{Introduction ${ }^{1}$}

This article considers structural economic dynamics (Pasinetti, 1993), in models with fixed capital and a choice of technique, of the production of commodities by means of commodities. Fluke switch points are described and catalogued. So-called 'perverse' phenomena studied in the Cambridge capital controversy (CCC) arise in the examples presented here. Cohen and Harcourt (2003) and Lazzarini (2011) survey the CCC. Like Samuelson (1966), I call results 'perverse' if they contradict obsolete teaching in marginalist economics. This article demonstrates that these 'perverse' results are not fluke cases.

Researchers in post Sraffian price theory have built up a theory of fixed capital as a type of joint production. Bidard (2004), Pasinetti (1980), and Schefold (1989) are some canonical references. This paper presents examples of pure fixed capital systems without

\footnotetext{
${ }^{1}$ No funding was provided for this research. The author declares no conflicts of interest. I thank Alfredo Amieva, Bertram Schefold, and an anonymous referee for encouragement and comments on a previous draft. Usual caveats apply.
} 
superimposed joint production. Furthermore, these examples are of non-interlocked systems in which old machines cannot be transferred among sectors. Joint utilization of machines does not exist in any process. Old machines cannot be consumer goods. In the examples, a single commodity is a consumption good and acts as numeraire. Old machines may be freely disposed of; no cost arises in junking a machine, including before its technical life is complete. Nice properties of single production systems generalize to such cases of fixed capital. In particular, the "determination of the cost-minimising technique is independent of the structure of requirements for use" (Huang, 2019). The costminimizing technique can be determined by the construction of the wage frontier (Bidard 2020).

A switch point is specified by the condition that at least two techniques are cost-minimizing at the switch point. A fluke switch point is an edge case in which a perturbation of selected model parameters creates a qualitative change in how the choice of technique varies with distribution. Vienneau (2018) partitions parameter spaces in models with circulating capital alone, with each partition corresponding to a fluke switch point. Within each region formed by these partitions, the choice of technique and the characteristics of switch points do not vary. Two types of graphs, qualitatively resembling, in some aspects, Figures 2 and 3 in Section 3.1, are introduced for visualizing the partitions. The fluke switch points defining partitions can be associated with the appearance of, for example, capital-reversing and reswitching. Four types of fluke switch points are particularly highlighted by the taxonomy introduced in Vienneau (2018): a pattern over the axis for the rate of profits, a pattern over the wage axis, a three-technique pattern, and a reswitching pattern. Combinations of these fluke cases provide additional fluke cases. Vienneau (2019) uses these methods to follow Garegnani (1970) in arguing that wages and employment are not explained by the interaction of the supply and demand for labor.

This article presents a first application to models of fixed capital of this taxonomy of fluke switch points and these methods for visualizing the resulting partition of parameter spaces. This article demonstrates that the four types of fluke switch points mentioned above can arise with models of fixed capital. Implications, not necessarily original, are drawn about the choice of the truncation of the operation of (or the economic life of) machines and about the adoption of roundabout techniques.

Technical progress is modeled in this article by decreases in coefficients of production or by increases from production processes of the amount of output of final goods. These production processes need not be part of a cost-minimizing technique while undergoing improvement. Exponential functions are used to group together coefficients of production that decay at the same rate under some model of technical progress. Other groupings and idealizations are certainly possible. Technical progress, in these sorts of models, can be said to occur in secular or slow time. The effect of such secular change on prices of production is such that 'perverse' results can emerge and vanish. The relationship of prices of production to market prices is not analyzed. In particular, no claims are made about how qualitative change in the choice of the cost-minimizing technique might impact market-price dynamics. 
The remainder of this article consists of three sections. The next section presents an overview of a general model of joint production. The third section illustrates four examples of models of fixed capital. One is of a model with one produced commodity that can be used for three years in production. The second example has two sectors. A long-lived machine is produced in the first sector and used in the second sector. The third is the simplest multisector model in which circulating and fixed capital can exist in both sectors. In the fourth example, managers of firms have a choice of directly producing a finished good without the assistance of fixed capital or adopting a technique in which a long-lived machine is produced to use in producing the finished good. The final section concludes.

\section{A Model of Joint Production}

Joint production arises when the output of a production process consists of two or more commodities, such as wool and mutton. Many issues arise in the analysis of prices of production under joint production, some of which can be ignored in certain models of fixed capital without superimposed joint production. Among these are the possible nonexistence of Sraffa's standard commodity (Manara, 1968), the possible existence of negative quantities in the standard commodity when it does exist (Sraffa, 1960), and the possibility of negative labor values (Steedman, 1981). There may be no market algorithm, such as that presented in Bidard (1997) or Vienneau (2017), that converges to the costminimizing technique. The analysis of the choice of technique cannot always be approached by the construction of the wage frontier with an arbitrary numeraire (Bidard and Klimovsky, 2004).

Table 1 - Variable Definitions

\begin{tabular}{cl}
\hline Variable & \multicolumn{1}{c}{ Definition } \\
\hline $\mathbf{q}$ & A column vector of levels of operation of each process. \\
\hline$c$ & The level of consumption per worker (numeraire units per person-year). \\
\hline$g$ & The steady-state rate of growth. \\
\hline $\mathbf{p}$ & A row vector of prices of production. \\
\hline$w$ & Wage (numeraire units per person-year). \\
\hline$r$ & Rate of profits. \\
\hline
\end{tabular}

For this exposition of joint production, I assume $n$ commodities can be produced by $m$ processes, where $n \leq m$. The technology is specified by the $m$-element row vector $\mathbf{a}_{0}$, the $n x m$ matrix $\mathbf{A}$, and the $n x m$ matrix $\mathbf{B}$. The element $a_{0, j}$ represents the quantity of labor needed as an input to operate the $j$ th process at a unit level, $a_{i, j}$ is the quantity of the $i$ th commodity provided as an input, and $b_{i, j}$ is the quantity of the $i$ th commodity produced by the $j$ th process at a unit level. Each process is assumed to obtain constant 
returns to scale (CRS) and to take a year to complete. This specification allows the possibility of the cost-minimizing technique being described by square input-output matrices. The proportions in which quantities are required for use are specified by the column vector $\mathbf{d}$. The vector $\mathbf{d}$ is also the commodity basket representing the numeraire.

What processes must be operated, and what are prices in a steady state? Table 1 defines the variables to be found in this model of the production of commodities. The model is open. Even when a solution exists, not all variables are determined. Accordingly, suppose the rate of growth and the rate of profits are given from outside the model. In Section 3, the rate of growth is taken to be zero and output per worker is evaluated in a comparison of stationary states. The variables solve the system of equalities and inequalities specified in Display 1 through Display 8:

$$
\begin{aligned}
& {[B-\boldsymbol{A} \cdot(1+g)] \cdot \boldsymbol{q} \geq c \cdot \boldsymbol{d}} \\
& \boldsymbol{a}_{0} \cdot \boldsymbol{q}=1 \\
& \boldsymbol{p} \cdot[\boldsymbol{B}-\boldsymbol{A} \cdot(1+r)] \leq w \cdot \boldsymbol{a}_{0} \\
& \boldsymbol{p} \cdot \boldsymbol{d}=1 \\
& \boldsymbol{p} \cdot[\boldsymbol{B} \cdot \boldsymbol{q}-\boldsymbol{A} \cdot(1+g) \cdot \boldsymbol{q}-c \cdot \boldsymbol{d}(t)]=0 \\
& {\left[\boldsymbol{p} \cdot \boldsymbol{B}-\boldsymbol{p} \cdot \boldsymbol{A} \cdot(1+r)-w \cdot \boldsymbol{a}_{0}\right] \cdot \boldsymbol{q}=0}
\end{aligned}
$$

For all $i, q_{i} \geq 0$

For all $j, p_{j} \geq 0$

Displays 1 and 2 specify the quantity system, while Displays 3 and 4 specify the price system. Displays 5 and 6 are duality conditions, and Displays 7 and 8 constrain levels of operation and prices to be non-negative. According to Display 1, the net output of each produced commodity either meets or exceeds the requirements for use. That is, each element of the column vector in the square brackets in Display 5 is non-negative. If the net output of a commodity exceeds its requirement for use, its price is therefore zero. This condition is known as the rule of free goods. Display 3 expresses the constraint that the revenue obtained from each process cannot exceed costs, including the profit calculated on the capital goods advanced. Thus, each element of the row vector in the square bracket in Display 6 is non-positive. If the cost of operating a process exceeds the revenues obtained in that process, the level of operation of that process must be zero.

\section{Fixed Capital}

Consider a production process which requires as input a new machine of a specified type. Labor works with other inputs and the new machine to produce some commodity, along with a machine a year older and of a specific history. The old machine is jointly produced with a finished good. Each old machine is jointly produced in a process in which a machine one year younger enters.

In a pure fixed-capital system (Kurz and Salvadori, 1995: 188; Schefold, 1989: 145146), each process produces exactly one finished good, such as a consumption good; a 
good used as circulating capital; or a new, possibly long-lived machine. Old machines are intermediate goods. Every finished good has exactly one primary process for producing it, in which an intermediate good does not enter as an input. In each sector, the secondary processes completely use up the old machine produced by the primary process in that sector, with no other intermediate goods as inputs. They produce the same finished good, possibly jointly with an intermediate good. Four simple examples of fixed capital are presented below to illustrate how fluke switch points can partition the parameter space.

Table 2 - Technology for Producing Widgets

\begin{tabular}{lccc}
\hline \multirow{2}{*}{ Input } & & Process & \\
\cline { 2 - 4 } & $(\mathbf{I})$ & $($ II $)$ & $a_{0,3}$ \\
\hline Labor & $a_{0,1}$ & $a_{0,2}$ & 0 \\
\hline New Widgets & 1 & 0 & 0 \\
\hline 1-Yr. Old Widgets & 0 & 1 & 1 \\
\hline 2-Yr. Old Widgets & 0 & 0 & \\
\hline Output & & & $b_{1,3}$ \\
\hline New Widgets & $b_{1,1}$ & $b_{1,2}$ & 0 \\
\hline 1-Yr. Old Widgets & 1 & 0 & 0 \\
\hline 2-Yr. Old Widgets & 0 & 1 & 0 \\
\hline
\end{tabular}

\subsection{A 'One-Good' Example}

Steedman (1994) provides an analysis of an extremely simple case of fixed capital of constant efficiency. Consider a 'one-commodity' economy in which labor and widgets are used to produce new widgets, the only consumption good. New widgets last several years when used in producing widgets. For concreteness, they last three years. In this generalization of Steedman's analysis, their efficiency can vary throughout their technical lifetime. Accordingly, Table 1 specifies the coefficients of production for three processes. A number of fluke switch points arise in this example, and they can be used to visualize how so-called perverse behavior can arise and disappear.

Firms are not required to operate all three processes. They can truncate the use of widgets after one or two years. The choice of technique in this model is equivalent to the choice of the economic life of a widget. In the Alpha technique, the widget is operated for one year; in the Beta technique, it is operated for two years; and in the Gamma technique, it is operated for the full three years.

A wage curve corresponds to each technique, as illustrated in Figure 1 for a particular set of coefficients of production. For the inequalities in Display 3, a system of equations is formed from the processes specified by the technique, and the left-hand side is set equal to the right-hand side for these processes. For the Alpha technique, Display 3 provides a single equation:

$p_{1, \alpha} \cdot(1+r)+w_{\alpha} \cdot a_{0,1}=p_{1, \alpha} \cdot b_{1,1}$ 
A system of two equations arises for the Beta technique:

$$
\begin{aligned}
& p_{1, \beta} \cdot(1+r)+w_{\beta} \cdot a_{0,1}=p_{1, \beta} \cdot b_{1,1}+p_{2, \beta} \\
& p_{2, \beta} \cdot(1+r)+w_{\beta} \cdot a_{0,2}=p_{1, \beta} \cdot b_{1,2}
\end{aligned}
$$

The system for the Gamma technique consists of three equations:

$$
\begin{aligned}
& p_{1, \gamma} \cdot(1+r)+w_{\gamma} \cdot a_{0,1}=p_{1, \gamma} \cdot b_{1,1}+p_{2, \gamma} \\
& p_{2, \gamma} \cdot(1+r)+w_{\gamma} \cdot a_{0,2}=p_{1, \gamma} \cdot b_{1,2}+p_{3, \gamma} \\
& p_{3, \gamma} \cdot(1+r)+w_{\gamma} \cdot a_{0,3}=p_{1, \gamma} \cdot b_{1,3}
\end{aligned}
$$

The equation for the numeraire in Display 4 provides another equation, resulting in a system, for each technique, for the variables consisting of prices of produced commodities, the wage, and the rate of profits. Under fairly general assumptions, given the rate of profits between zero and a certain maximum, the wage and prices of produced commodities are determined. The wage curve for a given technique depicts the wage as a function of the rate of profits.

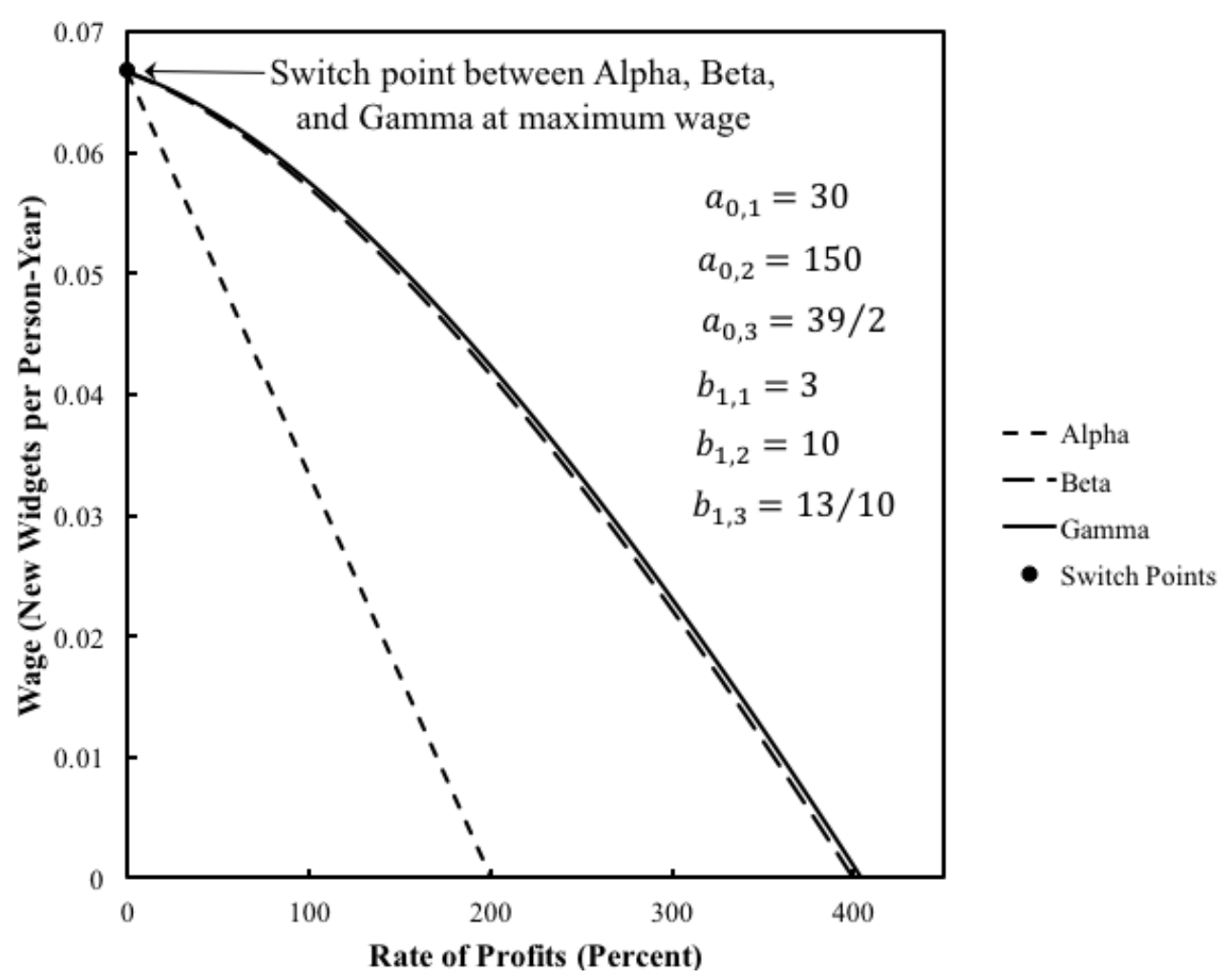

Figure 1 - A Three-Technique Pattern Over the Wage Axis

The wage frontier is the outer envelope of all wage curves. In models of circulating and fixed capital without superimposed joint production, the cost-minimizing technique, at a given rate of profits, is the technique which contributes its wage curve to the frontier at that rate. The Gamma technique is cost-minimizing in Figure 1 for all feasible rates of profits. Wage curves, when on the frontier, are declining functions of the rate of profits. At a switch point, more than one technique is cost-minimizing. At a rate of profits of zero in Figure 1, the Alpha, Beta, and Gamma techniques are all cost-minimizing. 
Several equivalent methods can be used to locate switch points. First, switch points can be found by finding the intersections of pairs of wage curves. One finds the zeros of a polynomial function. Second, one can find, in this case, the rates of profits at which the price of old widgets is zero, for the price system associated with a given technique. The Gamma technique is only cost-minimizing if the prices of one-year old and two-year old widgets are non-negative in the solution to the price system for the Gamma technique. The Beta technique is only cost-minimizing if the Gamma technique is not uniquely costminimizing, and the price of a one-year old widget is non-negative for the solution of the price system for the Beta technique. This approach, too, requires one to find the roots of polynomial equations. For the simple examples in this paper, these polynomials never exceed the fourth order, and they can be solved analytically. Presumably, more complicated examples with longer-lasting machines could yield wage curves with visual differences that are more dramatic, but they would require numerical methods for finding switch points. Nevertheless, parameter values that yield fluke switch points are mostly found by numerical methods, particularly by an algorithm for a binary search.

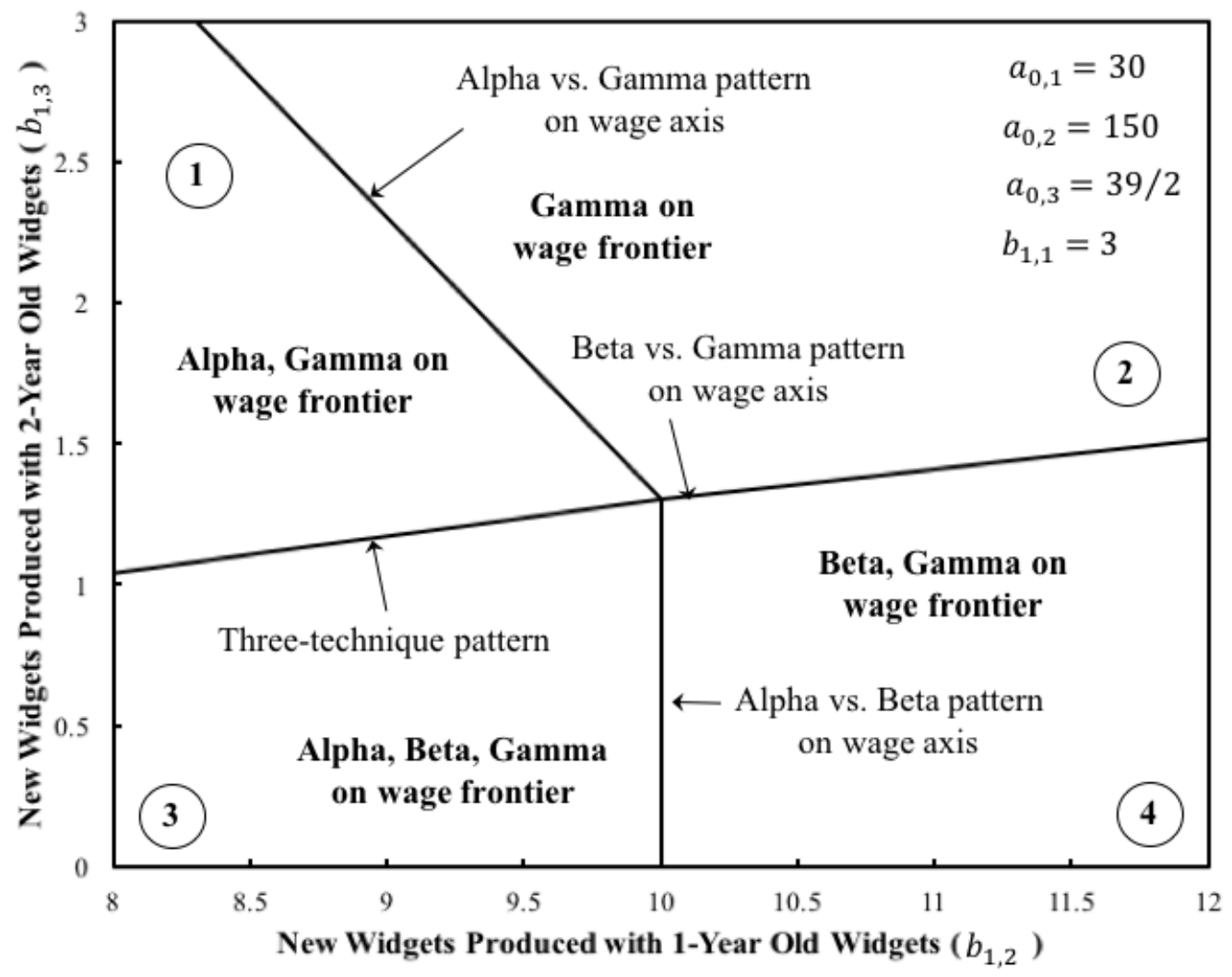

Figure 2 - Variation in the Wage Frontier with Selected Coefficients of Production

The single switch point in Figure 1 is a fluke case several times over. It is the intersection of three wage curves, not two. And the switch point is on the wage axis, occurring for a rate of profits of zero. These properties are destroyed by any variation in certain coefficients of production. Figure 2 illustrates variations in $b_{1,2}$ and $b_{1,3}$. The locations in parameter space for fluke switch points, which I call patterns of switch points, are shown. 
Consider parameters in Region 3, and suppose $b_{1,2}$ is increased. Eventually, a fluke case will arise in which the switch point between the Alpha and Beta technique is on the wage axis. When $b_{1,2}>10$, this switch point will no longer occur for a non-negative rate of profits. It will only be cost-minimizing to run widgets for two or three years, depending on distribution. On the other hand, consider an increase in $b_{1,3}$. The switch points between Alpha and Beta and between Beta and Gamma will eventually coincide, in a single switch point at a positive rate of profits. With any further increase in this parameter, it is no longer cost minimizing to run widgets for two years, whatever the distribution of income.

Just as a technique has an associated price system, so, given the rate of growth, it has an associated quantity system. One can form a system of linear equations for a technique and a stationary state from Displays 1 and 2. One can thereby obtain the level of consumption per worker, the gross outputs of the processes in the technique, and the quantity of capital goods used by these processes. One obtains prices of all commodities when solving the price system for a technique. A real Wicksell effect is the variation in the numeraire value of capital goods with the technique at a given rate of profits (Harris 1973). Around a switch point with a negative real Wicksell effect, a higher wage or lower rate of profits is associated with the adoption of a technique with a larger value of capital per person-year employed in a stationary state. Net output per person-year is also increased. Burmeister (1980) argues that a negative real Wicksell effect is the appropriate concept for formalizing the marginalist notion of capital deepening.

The structure in Figure 2 is generic in some sense. Three partitions of patterns over the wage axis intersect in the start of a ray that is a partition for a three-technique pattern. A corresponding structure can exist for patterns over the axis for the rate of profits.

Table 3 - Summary of 'One-Good' Results

\begin{tabular}{|c|c|c|c|}
\hline Region & Range & Technique & Summary \\
\hline \multirow{2}{*}{1} & $0 \leq r \leq r_{1}$ & Widgets operated for one year. & \multirow{2}{*}{$\begin{array}{l}\text { The switch point exhibits negative } \\
\text { real Wicksell effects. A larger rate of } \\
\text { profits is associated with a longer } \\
\text { economic life of a widget. }\end{array}$} \\
\hline & $r_{1} \leq r \leq R_{\gamma}$ & Widgets operated for three years. & \\
\hline 2 & $0 \leq r \leq R_{\gamma}$ & Widgets operated for three years. & No switch points. \\
\hline \multirow{3}{*}{3} & $0 \leq r \leq r_{1}$ & Widgets operated for one year. & \multirow{3}{*}{$\begin{array}{l}\text { Both switch points exhibit negative } \\
\text { real Wicksell effects. A larger rate of } \\
\text { profits is associated with a longer } \\
\text { economic life of a widget. }\end{array}$} \\
\hline & $r_{1} \leq r \leq r_{2}$ & Widgets operated for two years. & \\
\hline & $r_{2} \leq r \leq R_{\gamma}$ & Widgets operated for three years. & \\
\hline \multirow{2}{*}{4} & $0 \leq r \leq r_{1}$ & Widgets operated for two years. & \multirow{2}{*}{$\begin{array}{l}\text { The switch point exhibits negative } \\
\text { real Wicksell effects. A larger rate of } \\
\text { profits is associated with a longer } \\
\text { economic life of a widget. }\end{array}$} \\
\hline & $r_{1} \leq r \leq R_{\gamma}$ & Widgets operated for three years. & \\
\hline \multirow{3}{*}{5} & $0 \leq r \leq r_{1}$ & Widgets operated for three years. & \multirow{3}{*}{$\begin{array}{l}\text { The switch point at } r_{1} \text { exhibits nega- } \\
\text { tive real Wicksell effects; the switch } \\
\text { point at } r_{2} \text { exhibits positive real } \\
\text { Wicksell effects. Recurrence of trun- } \\
\text { cation recurs with reswitching. }\end{array}$} \\
\hline & $r_{1} \leq r \leq r_{2}$ & Widgets operated for one year. & \\
\hline & $r_{2} \leq r \leq R_{\gamma}$ & Widgets operated for three years. & \\
\hline
\end{tabular}


Table 3 summarizes the choice of technique in each region in Figure 2. (Region 5 is depicted in Figure 3 below.) Negative real Wicksell effects occur at all switch points in the four regions in Figure 2. According to traditional Austrian and marginalist dogma, one might expect an increase in capital intensity to go along with a longer economic life of a widget. This idea is proven to be untrue in Regions 1, 3, and 4. Is the jump over an economic life of two years in Region 1 surprising? Adjacent techniques on the wage frontier need not be near in a parameter space formed by coefficients of production. Continuous variation in the cost-minimizing technique along the wage frontier does not imply continuous variation in coefficients of production (Pasinetti, 1969; Bellino, 1993). In this case, the three-technique pattern of switch points illustrates how managers of firms come to eliminate the choice of the Beta technique.

To further explore the parameter space, a particular kind of technical change is introduced. The quantity of new widgets produced by the first process when operated at a unit level, $b_{1,1}$, is assumed constant. The quantity of new widgets produced by the other two processes is assumed to grow exponentially. Labor inputs fall exponentially. The values of coefficients of production are specified for $t=1$. Prices of production can now be found at each moment of time. Figure 3, which I call a pattern diagram, plots the maximum wage and the wage at switch points against time. The thin vertical lines partition time. Within each numbered region, the number and sequence of switch points along the wage frontier does not change. Region 5, as noted in Table 3, is an example of reswitching. A new kind of fluke switch point, a reswitching pattern, is indicated. For this fluke case, two wage curves are tangent at a switch point on the frontier.

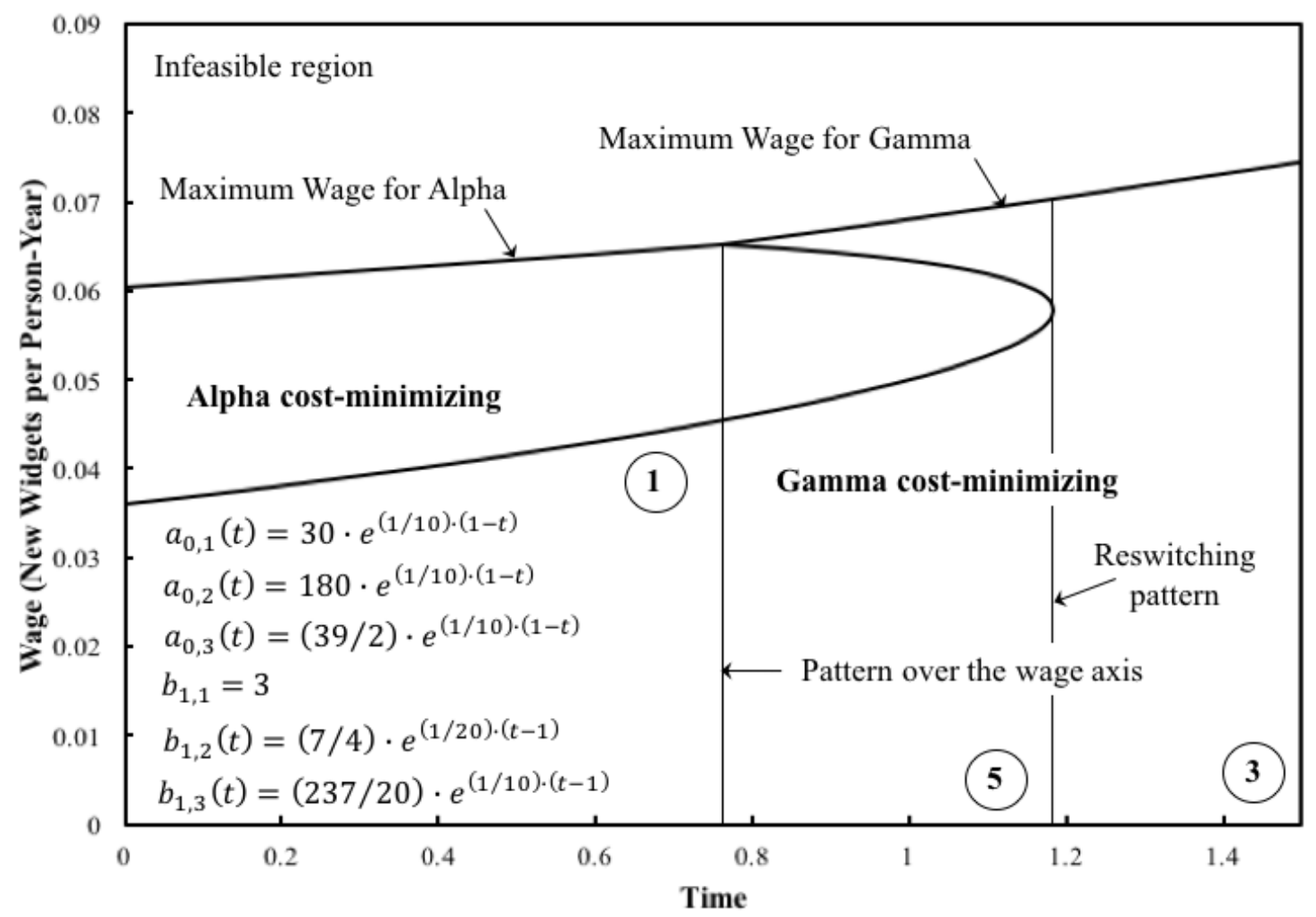

Figure 3 - Variation in the Wage Frontier with Technical Progress 
Figure 3 succinctly presents a visualization of the wage frontier at each point in time, while abstracting from some properties of the frontier. Slopes of wage curves, on or off the frontier, cannot be seen. In the range of parameters shown, the wage curve for Beta, which is not on the frontier, slopes upward for a small rate of profits. Varri (1974) demonstrates that this is possible off the frontier for models with fixed capital. In models with circulating capital alone, wage curves must slope down on and off the frontier. The convexity of the wage curves is also abstracted from in Figure 3. Price Wicksell effects, the variation in the numeraire value of capital goods with the rate of profits for a given technique, are related to the convexity of the wage curve. In the example, the capital intensity of the technique rises with the rate of profits for the Gamma technique in Region 1, and for both the Beta and Gamma techniques in Regions 3 and 4. I find it of greater interest that in Region 5, the switch point at the higher rate of profits or lower wage exhibits a positive real Wicksell effect, also known as capital reversing. Around the switch point, a decrease in the rate of profits or increase in the wage is associated with a decrease in output per worker and a decrease in the economic life of a widget. Recurrence of truncation arises with reswitching in this example.

Of the switch points examined so far, only the one at $r_{1}$ in Region 5 conforms to obsolete marginalist intuition. The unfounded marginalist intuition is that saving increases the quantity of capital, measured, say, in terms of the value of new widgets per person-year. Even though the evaluation of old widgets in terms of new widgets per old widget can only be performed with prices that emerge endogenously out of the model, marginalist economists once hoped that one could still talk meaningfully about the supply of 'real' capital. An increased supply would drive the rate of profits down. A lower rate would then be associated with the adoption of a technique in which the value of capital per head and the economic life of the widget are increased. The switch point at the rate of profits $r_{1}$ is the only illustrated switch point in which a lower rate of profits is associated with an increase in the economic life of a widget. Even so, the increase of the economic life of the widget, perhaps surprisingly, skips from one year to three years, hardly a marginal adjustment.

This 'one-good' example demonstrates that a higher wage or lower rate of profits is not necessarily associated with a longer economic life of a machine. A longer economic life of a machine can be accompanied by the employment of less capital per worker. Reswitching, the recurrence of truncation, and capital reversing are all illustrated in the example. See Baldone (1974) for another numerical example of the recurrence of truncation.

\subsection{An Example with One Type of Machine}

Rather than provide a more comprehensive analysis of the parameter space of the 'onegood' example, I skip to an extension of a reswitching example from Schefold (1980 and 1989). Table 4 presents coefficients of production for this example. The units in which corn is measured are normalized such that the output of corn for the process using the 
Table 4 - Technology for Producing a Net Product of Corn

\begin{tabular}{lccc}
\hline \multirow{2}{*}{ Input } & Machine Sector & \multicolumn{2}{c}{ Corn Sector } \\
\cline { 2 - 4 } & $a_{0,1}=\frac{1}{10} e^{1-\sigma \cdot t}$ & $a_{0,2}=\frac{43}{40} e^{1-\phi \cdot t}$ & Another Process \\
\hline Labor & $a_{1,1}=\frac{1}{16} e^{1-\sigma \cdot t}$ & $a_{1,2}=\frac{1}{16} e^{1-\phi \cdot t}$ & $a_{0,3}=e^{1-\phi \cdot t}$ \\
\hline Corn & 0 & 1 & $a_{1,3}=\frac{1}{4} e^{1-\phi \cdot t}$ \\
\hline New Machines & 0 & 0 & 0 \\
\hline Old Machines & 0 & $b_{1,2}=1$ & 1 \\
\hline Output & 1 & 0 & $b_{1,3}=1$ \\
\hline Corn & 0 & 1 & 0 \\
\hline New Machines & 0 & 0 \\
\hline Old Machines & 0 & 0
\end{tabular}

new machine is unity. Despite variations of inputs, the output of corn from the machine does not vary with age. A particular form of technical process is assumed. Inputs for each process continually decline. The rate of the decrease in the machine sector need not be equal to the rate of decrease in the corn sector. With these assumptions, the parameter space is reduced to one of two dimensions. The Alpha technique consists of the machineproducing process and the first corn-producing process. In the Beta technique, all three processes are operated.

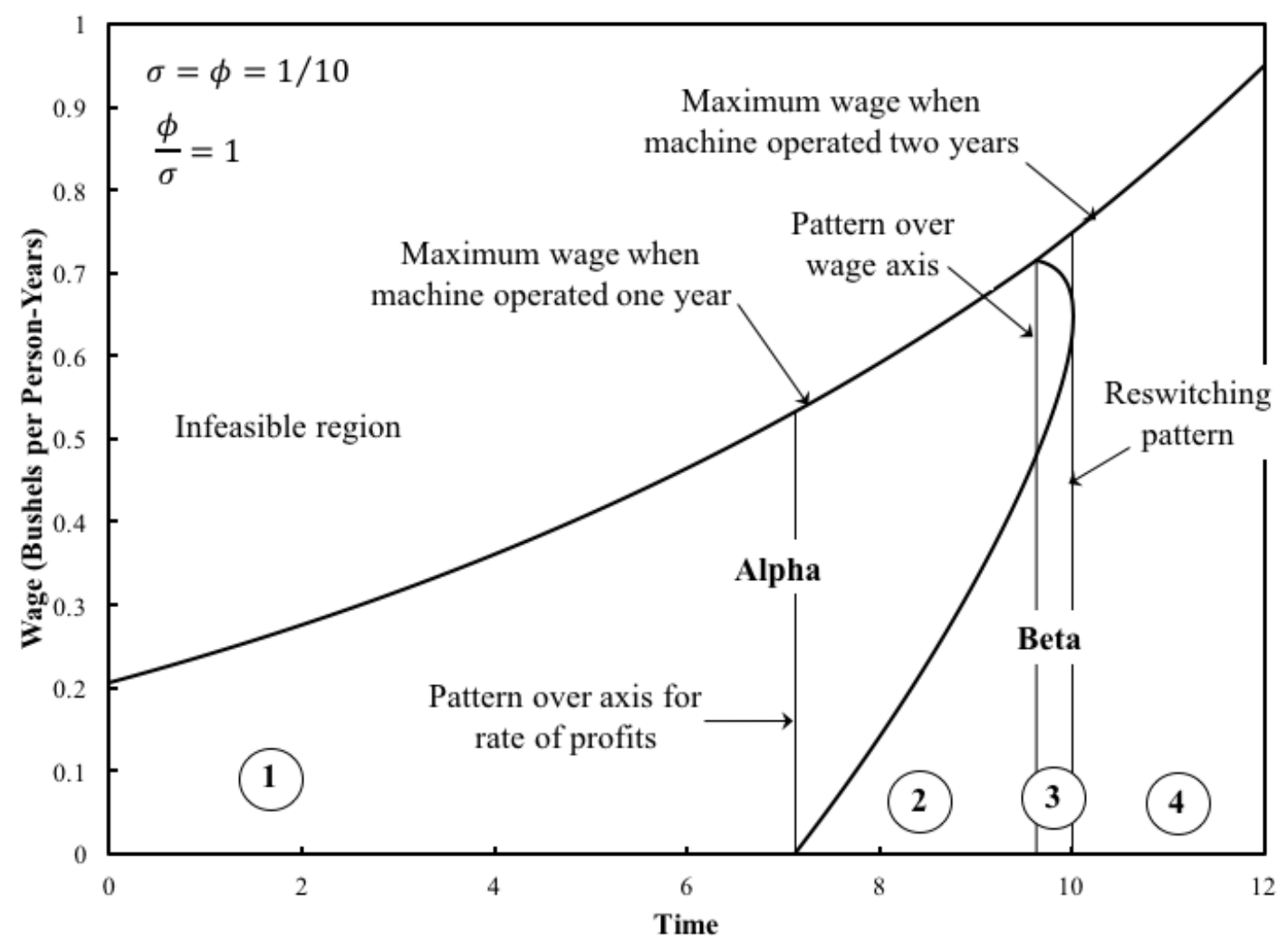

Figure 4 - A Pattern Diagram in the Extended Schefold Example 
Figure 4 illustrates how the analysis of the choice of technique varies with technical progress when the rate of decrease of coefficients of production is the same, at ten percent, for inputs in the machine and corn sectors. The coefficients of production for Schefold's example occur at a time of 10, while the reswitching pattern occurs at a time of approximately 10.01202. These times are hardly distinguishable to the eye on the time axis here. The fluke switch point which I call a pattern over the axis for the rate of profits arises in this example.

Table 5 - Summary of Results for the Extended Schefold Example

\begin{tabular}{|c|c|c|c|}
\hline Region & Range & Technique & Summary \\
\hline 1 & $0 \leq r \leq R_{\alpha}$ & Machine operated for one year. & No switch points. \\
\hline \multirow{2}{*}{2} & $0 \leq r \leq r_{1}$ & Machine operated for one year. & \multirow{2}{*}{$\begin{array}{l}\text { The switch point exhibits negative real } \\
\text { Wicksell effects. A larger rate of prof- } \\
\text { its is associated with a longer economic } \\
\text { life of a machine. }\end{array}$} \\
\hline & $r_{1} \leq r \leq R_{\beta}$ & Machine operated for two years. & \\
\hline \multirow{3}{*}{3} & $0 \leq r \leq r_{1}$ & Machine operated for two years. & \multirow{3}{*}{$\begin{array}{l}\text { Reswitching, capital reversing, and the } \\
\text { recurrence of truncation. The switch } \\
\text { point at the higher rate of profits exhib- } \\
\text { its a positive real Wicksell effect; } \\
\text { Around it, a larger rate of profits is as- } \\
\text { sociated with a longer economic life of } \\
\text { a machine. }\end{array}$} \\
\hline & $r_{1} \leq r \leq r_{2}$ & Machine operated for one year. & \\
\hline & $r_{2} \leq r \leq R_{\beta}$ & Machine operated for two years. & \\
\hline 4 & $0 \leq r \leq R_{\beta}$ & Machine operated for two years. & No switch points. \\
\hline \multirow{2}{*}{5} & $0 \leq r \leq r_{1}$ & Machine operated for two years. & \multirow{2}{*}{$\begin{array}{l}\text { The switch point exhibits negative real } \\
\text { Wicksell effects. A smaller rate of } \\
\text { profits is associated with a longer eco- } \\
\text { nomic life of a machine. }\end{array}$} \\
\hline & $r_{1} \leq r \leq R_{\alpha}$ & Machine operated for one year. & \\
\hline
\end{tabular}

Table 5 summarizes properties of the regions shown in the partitioned space in Figure 4. At the start of time, operating the machine for one year is cost-minimizing, whatever the distribution of income. At the end of time, increased productivity leads to operating the machine for the full two years being cost-minimizing. Reswitching arises during one of two regions in transition between these two extreme regions. The switch point in Region 2 is 'non-perverse' inasmuch as a higher wage or lower rate of profits is associated with more net output per person-year. But see Figure 6 below.

Figure 5 depicts how the two-dimensional parameter space is partitioned by the fluke switch points that I call patterns of switch points. In each numbered region, the variation of the cost-minimizing technique with income distribution is qualitatively invariant. The number and sequence of switch points along the wage frontier does not vary, although the specific locations of switch points change. The dashed line is a ray from the origin along which the rate of decrease of coefficients of production in the machine sector is equal to the rate of decrease in the corn sector. It corresponds to Figure 4. This ray traverses the first four numbered regions in order. Schefold found a reswitching example in the narrow wedge in the lower left of Region 3, but any point in Region 3 is a reswitching example. 


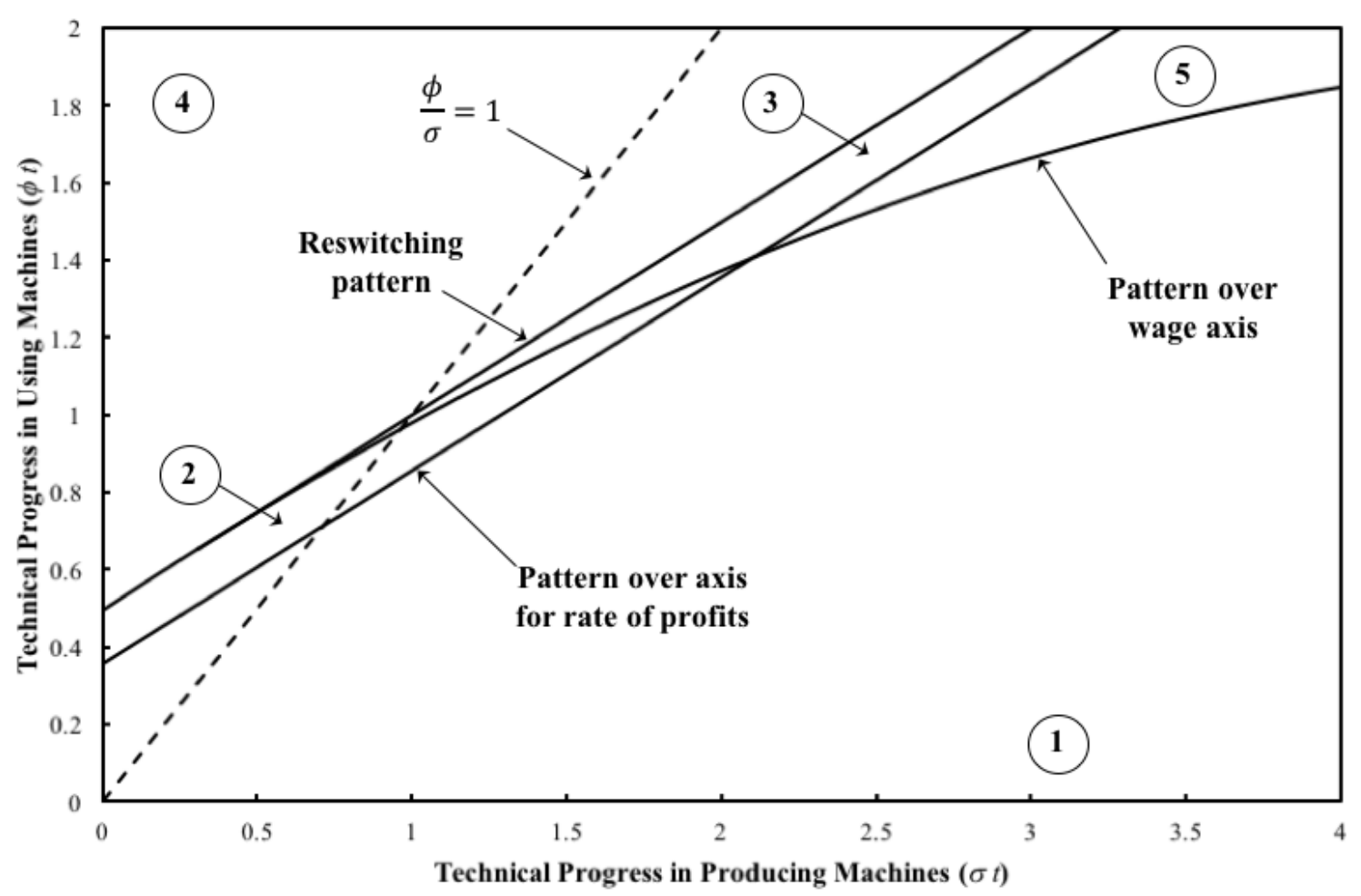

Figure 5 - A Two-Dimensional Pattern Diagram in the Extended Schefold Example
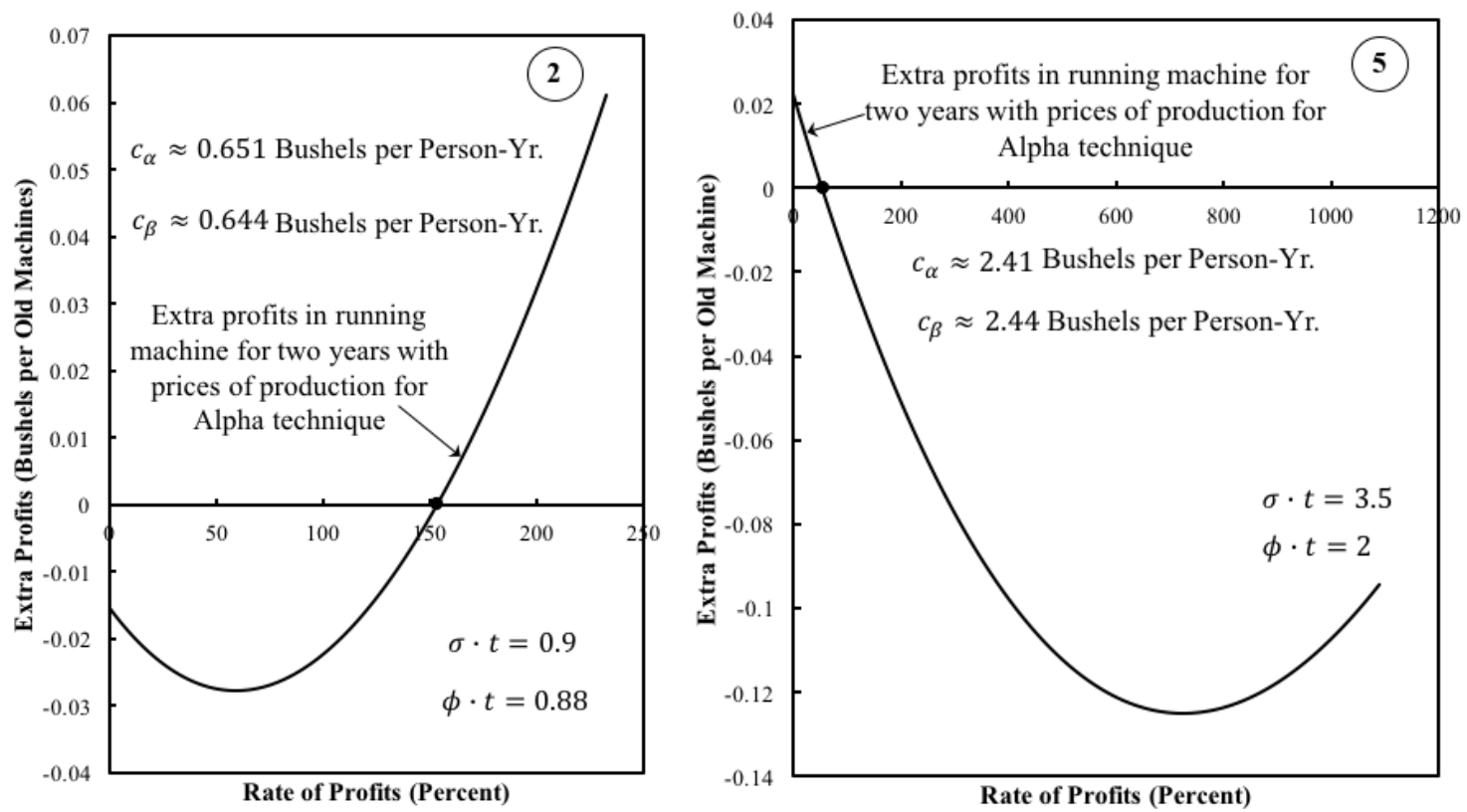

Figure 6 - Regions 2 and 5 in the Extended Schefold Example

Comparing and contrasting the single switch point in Regions 2 and 5 emphasizes one lesson drawn from Section 3.1. Figure 6 illustrates the analysis of the choice of technique in these regions. When the machine is junked after one year, the price of an old machine is zero. Figure 6 shows extra profits in operating the machine for the second year with prices of production in this case. Around the switch point in Region 2, it pays to run the machine for a second year for lower wages or higher rates of profits. On the other hand, 
around the switch point in Region 5, it pays to run the machine for the second year at higher wages or lower rates of profits.

Around the switch points in both Regions 2 and 5, a higher wage or lower rate of profits is associated with cost-minimizing firms hiring less labor, given net output. As one might expect, the adoption of a less labor-intensive technique is associated with greater net output per worker. It seems that the economic life of a machine cannot be mapped to the capital-intensity of a technique. Adopting a technique in which a machine is run longer is not necessarily more capital-intensive in that it does not necessarily raise output per worker for the economy as a whole. This counter-intuitive result, at least by traditional marginalist and Austrian teaching, obtains in Region 2.

As with the 'one good' example, this extension of Schefold's example demonstrates that an increased economic life of a machine can be associated with both negative and positive real Wicksell effects. Figure 6 provides a visual demonstration around 'non-perverse' switch points. The non-correlation of the increased life of a machine with capitalintensity is thus independent of reswitching and capital-reversing.

\subsection{An Example with Circulating and Fixed Capital in All Sectors}

For another example, consider the simplest multisector model in which circulating and fixed capital exist in all sectors. One sector produces a machine which lasts for two years. The other sector produces corn, which acts as both circulating capital and as the consumption good. Once a machine is used in the production of a finished good, it cannot be transferred to the other sector. Table 6 specifies the coefficients of production for the four production processes in this example, while Table 7 specifies the processes operated in each of the four techniques that allow for the self-reproduction of this economy.

Table 6 - Technology in a Two-Sector Model

\begin{tabular}{lcccc}
\hline & Processes in Machine Sector & \multicolumn{2}{c}{ Processes in Corn Sector } \\
\cline { 2 - 5 } Inputs & $(\mathbf{I})$ & $($ II $)$ & $($ III $)$ & $($ IV) \\
\hline Labor & $a_{0,1}$ & $a_{0,2}$ & $a_{0,3}$ & $a_{0,4}$ \\
\hline Corn & $a_{1,1}$ & $a_{1,2}$ & $a_{1,3}$ & $a_{1,4}$ \\
\hline New Machines & 1 & 0 & 1 & 0 \\
\hline Old Machines-A & 0 & 1 & 0 & 0 \\
\hline Old Machines-B & 0 & 0 & 0 & 1 \\
\hline Outputs & 0 & 0 & $b_{1,3}$ & $b_{1,4}$ \\
\hline Corn & $b_{2,1}$ & $b_{2,2}$ & 0 & 0 \\
\hline New Machines & 1 & 0 & 0 & 0 \\
\hline Old Machines-A & 0 & 0 & 1 & 0 \\
\hline Old Machines-B & & 0 & 0 \\
\hline
\end{tabular}


Table 7 - Techniques in the Two Sector Example

\begin{tabular}{cc}
\hline Technique & Processes \\
\hline Alpha & $(\mathrm{I}),(\mathrm{III})$ \\
\hline Beta & $(\mathrm{I}),(\mathrm{II}),(\mathrm{III})$ \\
\hline Gamma & $(\mathrm{I}),(\mathrm{III}),(\mathrm{IV})$ \\
\hline Delta & $(\mathrm{I}),(\mathrm{II}),(\mathrm{III}),(\mathrm{IV})$ \\
\hline
\end{tabular}

Figure 7 shows the results of varying $a_{1,2}$ for specific values of the remaining parameters. For variety, the ordinate is the rate of profits instead of the wage. A decrease in this coefficient of production corresponds to an increase in productivity. To the right, the machine is truncated in the machine sector, but run for its full lifetime in the corn sector for a high enough rate of profits. To the left, the machine is truncated in the corn sector, but run for its full lifetime in the machine sector at high rates of profits. The diagram portrays intermediate regions as well.

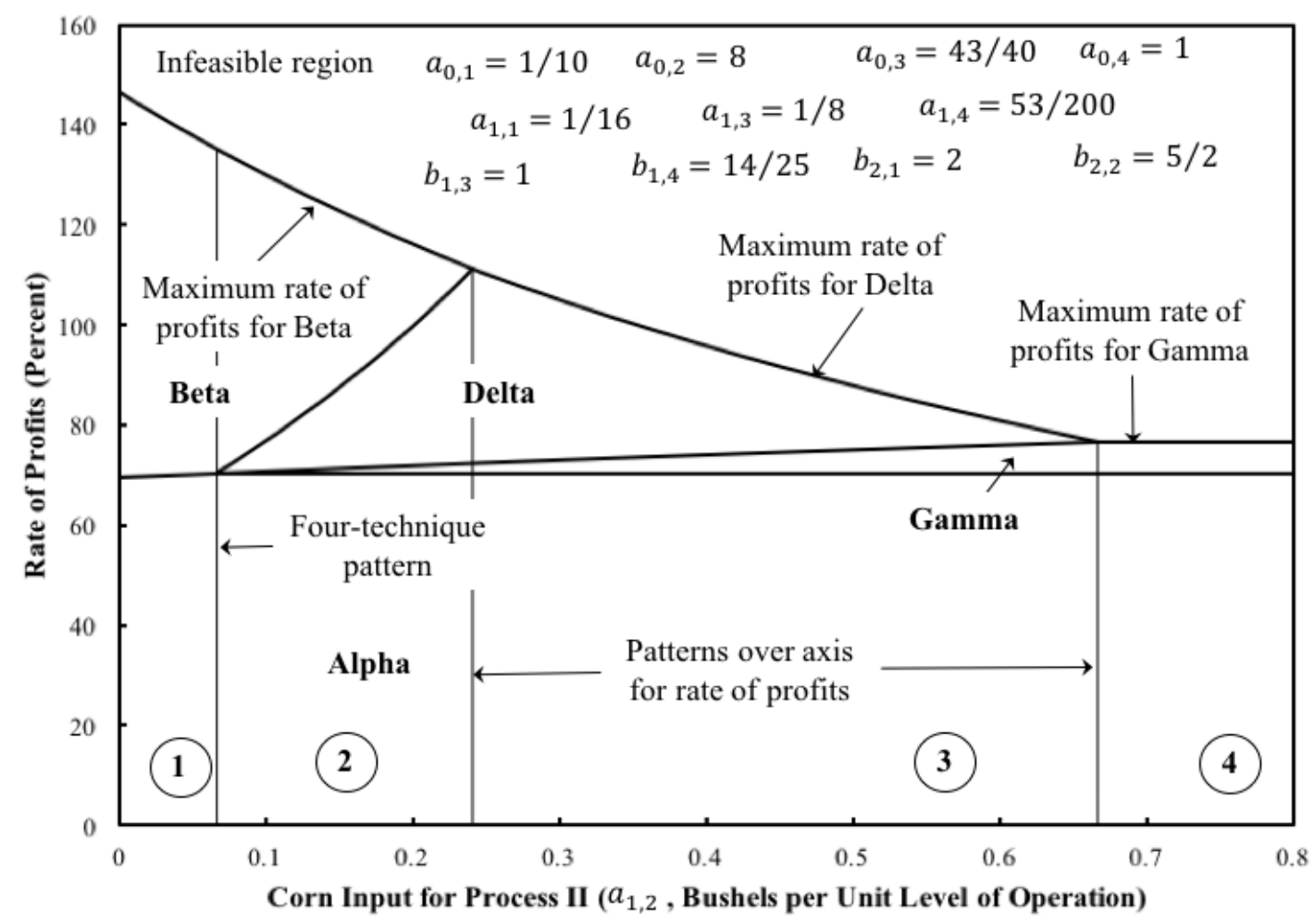

Figure 7 - A Pattern Diagram in the Two-Sector Example

A new fluke case is seen here at the partition of Regions 1 and 2. Four wage curves intersect at a single switch point. At the switch point, the wage is the same for all techniques. In particular, the wage for the Alpha and Delta techniques is the same:

$w_{\alpha}\left(r_{1}\right)=w_{\delta}\left(r_{1}\right)$

Firms are therefore indifferent in both sectors about truncating the operation of the machine or operating it for its full life. The price of both types of one-year old machines is 
zero. The condition in Equation 15 is sufficient to ensure that the Beta and Gamma techniques are also cost-minimizing at this switch point.

In Region 2, the operation of the machine in the corn sector is truncated for both low and high rates of profits, but not at intermediate rates of profits. All switch points for this example, with these coefficients of production, have negative real Wicksell effects. This is not an example of capital reversing. Likewise, reswitching does not arise for these coefficients of production. Thus, the recurrence of truncation is possible with neither reswitching nor capital reversing. Table 8 summarizes how the economic life of a machine varies with the rate of profits in both sectors in the four regions in Figure 7.

Table 8 - Summary of Results for The Two-Sector Example

\begin{tabular}{|c|c|c|c|}
\hline Region & Range & Technique & Summary \\
\hline & $0 \leq r \leq r_{1}$ & Machine truncated in both sectors. & \multirow{2}{*}{$\begin{array}{l}\text { A larger rate of profits is associated } \\
\text { with a longer economic life of a } \\
\text { machine in machine sector. }\end{array}$} \\
\hline & $r_{1} \leq r \leq R_{\beta}$ & Machine truncated in corn sector. & \\
\hline \multirow{4}{*}{2} & $0 \leq r \leq r_{1}$ & Machine truncated in both sectors. & \multirow{4}{*}{$\begin{array}{l}\text { Larger rate of profits associated } \\
\text { with longer economic life of ma- } \\
\text { chine in machine sector; Recur- } \\
\text { rence of truncation in corn sector. }\end{array}$} \\
\hline & $r_{1} \leq r \leq r_{2}$ & Machine truncated in machine sector. & \\
\hline & $r_{2} \leq r \leq r_{3}$ & Machine not truncated in either sector. & \\
\hline & $r_{3} \leq r \leq R_{\beta}$ & Machine truncated in corn sector. & \\
\hline \multirow{3}{*}{$J$} & $0 \leq r \leq r_{1}$ & Machine truncated in both sectors. & \multirow{3}{*}{$\begin{array}{l}\text { Larger rate of profits associated } \\
\text { with longer economic life of ma- } \\
\text { chine in both sectors. }\end{array}$} \\
\hline & $r_{1} \leq r \leq r_{2}$ & Machine truncated in machine sector. & \\
\hline & $r_{2} \leq r \leq R_{\delta}$ & Machine not truncated in either sector. & \\
\hline & $0 \leq r \leq r_{1}$ & Machine truncated in both sectors. & \multirow{2}{*}{$\begin{array}{l}\text { A larger rate of profits is associated } \\
\text { with a longer economic life of a } \\
\text { machine in corn sector. }\end{array}$} \\
\hline & $r_{1} \leq r \leq R_{\gamma}$ & Machine truncated in machine sector. & \\
\hline
\end{tabular}

\subsection{An Example of 'Roundabout' Production}

In demonstrating the lack of foundation for claims of the Austrian school about the supposed relationships between a greater supply of capital, a consequent lower rate of profits, and a longer period of production, I have so far only presented examples in which the economic life of an existing machine can be extended or truncated. Schefold (1980: 170) interprets a more roundabout technique as one in which a long-lived machine is used to produce a finished good that previously was produced directly without the aid of fixed capital or, at least, with a different and inferior machine. A final example extends Schefold's illustration of the difficulty in sustaining the Austrian claim.

The second, third, and fourth processes in the technology (Table 9) constitute the corn sector. In Process II, corn is produced from inputs of labor and corn, without fixed capital. The Alpha technique (Table 10) consists of Process II alone. A machine sector, composed of Process I, exists in the Beta and Gamma techniques. The technical life of the machine is two years. The machine is truncated to one year in the Beta technique. 
Table 9 - Technology in an Example of Roundabout Production

\begin{tabular}{lcccc}
\hline & \multicolumn{3}{c}{ Processes } & \\
\cline { 2 - 5 } Inputs & $(\mathbf{I})$ & $(\mathbf{I I})$ & $(\mathbf{I I I})$ & $(\mathbf{I V})$ \\
\hline Labor & $a_{0,1}$ & $a_{0,2}$ & $a_{0,3}$ & $a_{0,4}$ \\
\hline Corn & $a_{1,1}$ & $a_{1,2}$ & $a_{1,3}$ & $a_{1,4}$ \\
\hline New Machines & 0 & 0 & 1 & 0 \\
\hline Old Machines & 0 & 0 & 0 & 1 \\
\hline Outputs & 0 & 1 & $b_{1,3}=1 / 2$ & $b_{1,4}=1 / 2$ \\
\hline Corn & 1 & 0 & 0 & 0 \\
\hline New Machines & 0 & 0 & 1 & 0 \\
\hline Old Machines & & & & \\
\hline
\end{tabular}

Table 10 - Techniques in the Example of Roundabout Production

\begin{tabular}{cc}
\hline Technique & Processes \\
\hline Alpha & (II) \\
\hline Beta & (I), (III) \\
\hline Gamma & (I), (III), (IV) \\
\hline
\end{tabular}

Suppose the coefficients of production for inputs of labor and circulating capital decrease ten percent per year. Figure 8 shows the variation in the choice of technique for a specific configuration of coefficients of production. Schefold's example of triple switching occurs at $t=10$. Figure 9 graphs the wage frontier here, in which the wage curves for the Alpha and Gamma techniques are difficult for the eye to distinguish.

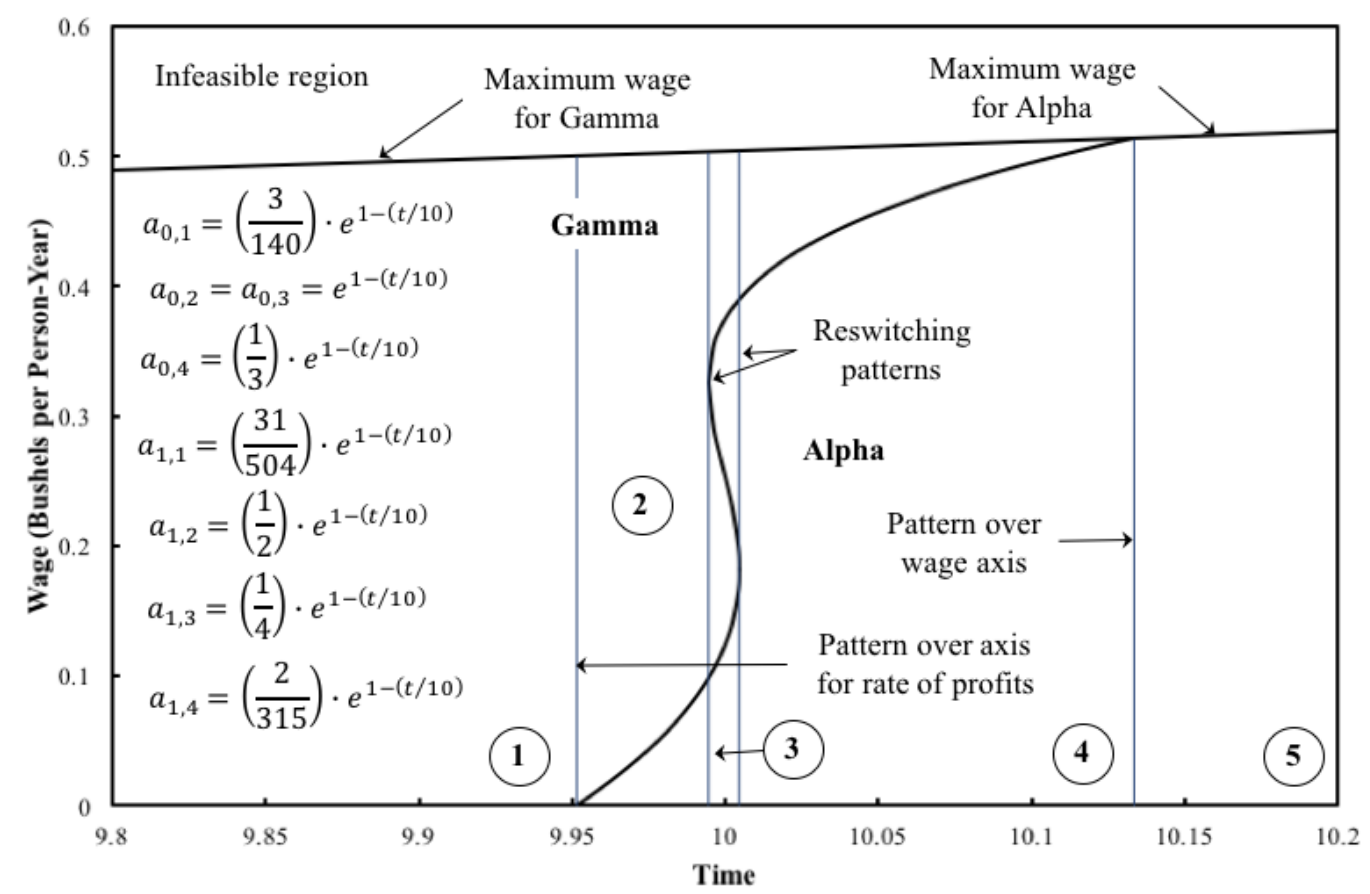

Figure 8 - A Pattern Diagram for the Example of Roundabout Production 


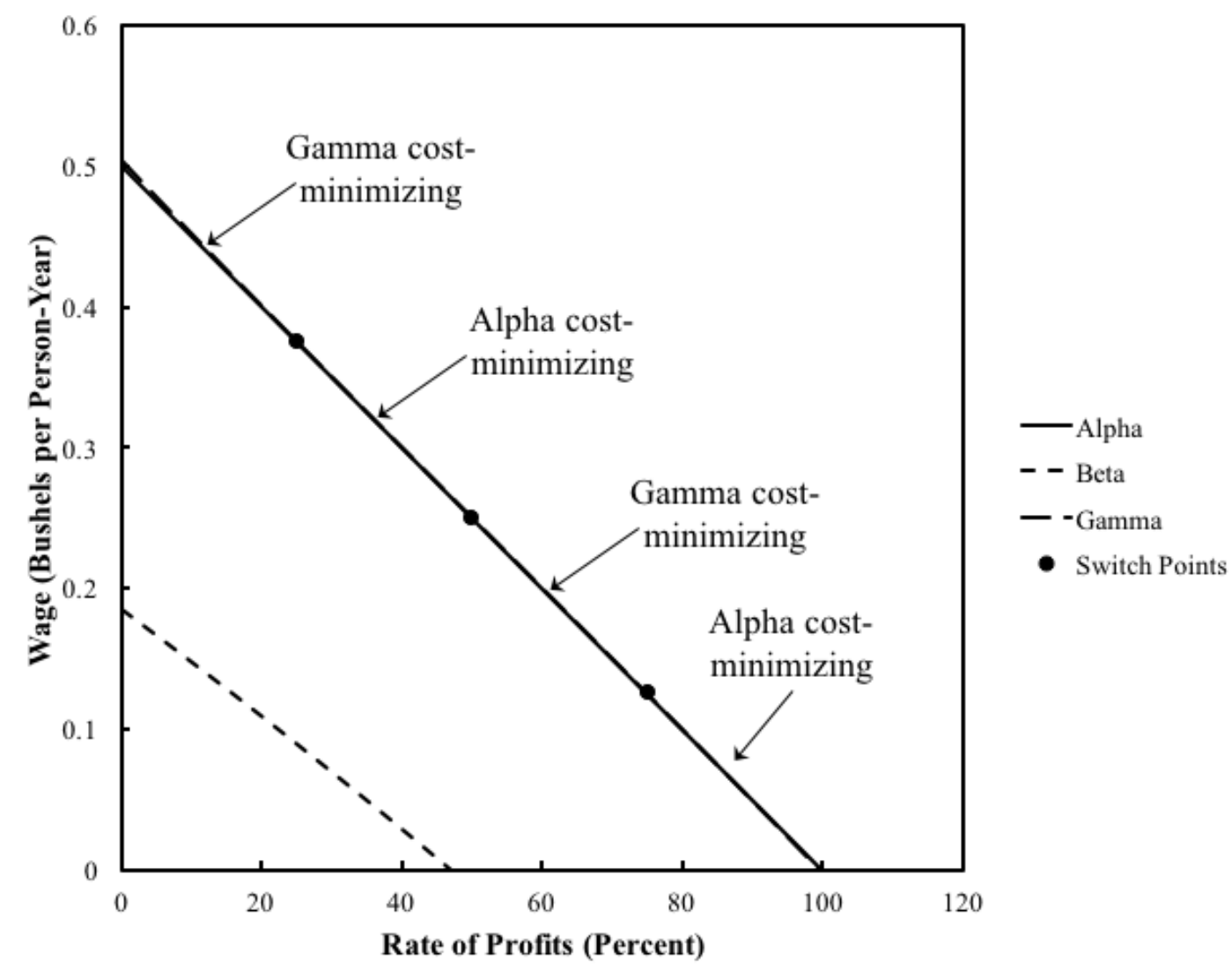

Figure 9 - Wage Curves in the Example of Roundabout Production

With this specification of parameters and technical progress, the non-roundabout process Alpha eventually replaces the roundabout process Gamma, whatever the distribution of income. Triple switching appears in the middle of the three transient regions. The patterns of switch points illustrate one manner in which triple-switching can appear. This example continues to illustrate how combinations of patterns of switch points can illuminate the effects of technical change.

In Regions 2, 3, and 4, the Alpha technique, in which corn is produced without the use of a machine, is cost-minimizing at the highest rate of profits, where the wage is zero. Around the only switch point in each of Regions 2 and 4, a higher wage or lower rate of profits is indeed associated with a more roundabout technique, and the more roundabout technique has a higher level of consumption per person-year in a stationary state. The Austrian claim is also illustrated at the lowest and highest switch point in Region 2. But it is invalidated for the middle switch point. Around this switch point, a higher wage or lower rate of profits is associated with the replacement of a roundabout technique by the direct production of the consumer commodity.

\section{Conclusion}

This article demonstrates, by means of numerical examples, that fluke switch points can arise in simple models of fixed capital without superimposed joint production. Fluke cases 
are crucial insofar as they partition the parameter space into regions in which the choice of technique and the characteristics of switch points do not vary. Furthermore, this analysis re-iterates that there really is nothing 'perverse' or 'paradoxical' about reswitching, capital-reversing, and the recurrence of truncation, since these phenomena are not fluke cases.

In these simple models of fixed capital, the choice of technique is mostly a matter of the choice of truncation, of deciding on the economic life of a machine. In the final example above, the choice of technique also includes deciding on whether to operate a machine at all. A decreased rate of profits can be associated with a cost-minimizing choice to truncate the operation of a machine. Truncation need not be continuous; a continuous variation in the rate of profits can result in the economic life of the machine varying from, say, one to three years. Truncation can be associated with either an increase or a decrease in the capital intensity of the chosen technique. This association, like the recurrence of the period of truncation, is independent of reswitching and capital-reversing. A non-monotonic variation of the economic life of a machine with the rate of profits without the recurrence of truncation is also compatible with the absence of reswitching and capitalreversing. One can demonstrate this by extending the example in the appendix of Baldone (1974), in the same way Schefold's reswitching example was extended in Section 3.2, to find a region in which the optimal life of a machine varies from two years to three years to one year along the wage frontier. Furthermore, the adoption of a more roundabout technique is also not necessarily associated with a lower rate of profits.

These results re-iterate that no necessary connection exists between employing or lengthening the economic life of a machine and an increase in the use of 'capital'. BöhmBawerk ([1889] 1959) was incorrect not merely because of the difficulty of defining a quantitative measure of the average period of production. His intuition, and not just his, on capital as a tool of production and as a source of interest income was itself incorrect. Neither the adoption of long-lived machinery in production nor the extension of the economic life of existing machinery have any necessary association with a lower interest rate or an increase in capital intensity.

\section{References}

Baldone, S. (1974), Il capitale fisso nello schema teorico di Piero Sraffa, Studi Economici, XXIV(1): 45-106. Trans. in Pasinetti (1980).

Bellino, E. (1993), Continuous switching of techniques in linear production models, Manchester School, 61(2): 185-201.

Bidard, C. (1997), Pure joint production, Cambridge Journal of Economics, 21(6): 685-701.

Bidard, C. (2004), Prices, Reproduction, Scarcity, Cambridge, Cambridge University Press. 
Bidard, C. (2020), The wage-minimisation property, EconomiX Working Papers 202017, University of Paris Nanterre.

Bidard, C. and Klimovsky, E. (2004), Switches and fake switches in methods of production, Cambridge Journal of Economics, 28(1): 89-97.

Böhm-Bawerk, E. von ([1889] 1959), Capital and Interest, South Holland, Illinois, Libertarian Press.

Burmeister, E. (1980), Capital Theory and Dynamics, Cambridge, Cambridge University Press.

Cohen, A.J. and Harcourt, G.C. (2003), Whatever happened to the Cambridge capital controversies?, Journal of Economic Perspectives, 17(1): 199-214.

Garegnani, P. (1970), Heterogeneous capital, the production function and the theory of distributio, Review of Economic Studies, 37(3): 407-436.

Harris, D.J. (1973), Capital, distribution, and the aggregate production function, American Economic Review, 63(1): 100-113.

Huang, B. (2019), Revisiting fixed capital models in the Sraffa framework, Economia Politica, 36: 351-371.

Kurz, H.D. and Salvadori, N. (1995), Theory of Production: A Long-Period Analysis, Cambridge, Cambridge University Press.

Lazzarini, A. (2011), Revisiting the Cambridge Capital Theory Controversies: A Historical and Analytical Study, Pavia University Press.

Manara, C.F. (1968), Il modello di Sraffa per la produzione congiunta di merci a mezzo di merci, L'Industria, 1: 3-18. Trans. in Pasinetti (1980).

Pasinetti, L.L. (1969), Switches of technique and the 'rate of return' in capital theory, Economic Journal, 79(315): 508-531.

Pasinetti, L.L., (1980) (ed.), Essays on the Theory of Joint Production, New York, Columbia University Press.

Pasinetti, L.L. (1993), Structural Economic Dynamics: A Theory of the Economic Consequences of Human Learning, Cambridge, Cambridge University Press.

Samuelson, P.A. (1966), A summing up, Quarterly Journal of Economics, 80(4): 568-583.

Schefold, B. (1980), Fixed capital as a joint product and the analysis of accumulation with different forms of technical progress, in Pasinetti (1980).

Schefold, B. (1989), Mr. Sraffa on Joint Production and other Essays, London, UnwinHyman.

Sraffa, P. (1960), Production of Commodities by Means of Commodities. Prelude to a Critique of Economic Theory, Cambridge, Cambridge University Press.

Steedman, I. (1981), Marx after Sraffa, London, Verso. 
Steedman, I. (1994), 'Perverse' behavior in a 'one-commodity' model, Cambridge Journal of Economics, 18(3): 299-311.

Varri, P. (1974), Prezzi, saggio del profitto e durata del capitale fisso nello schema teorico di Piero Sraffa, Studi Economici, XXIX(1): 5-44. Trans. in Pasinetti (1980).

Vienneau, R.L. (2017), The choice of technique with multiple and complex interest rates, Review of Political Economy, 29(3): 440-453.

Vienneau, R.L. (2018), Normal forms for switch point patterns. Review of Behvioural Economics, 5(2): 169-195.

Vienneau, R.L. (2019), Structural economic dynamics, markups, real Wicksell effects, and the reverse substitution of labor, Structural Change and Economic Dynamics, 50: 216-226. 
Author contact information:

Robert L. Vienneau

209 Maple St.

Rome, NY 13440 (USA)

rvien@dreamscape.com 